\title{
PKMS Braille Digital Marketing UMKM Al Mumtaz Eduwisata Difabel Penyandang Disabilitas Tunanetra dan Daksa Ringan Era New Normal di Kabupaten Banyuwangi
}

\author{
Putri Robiatul Adawiyah $^{1 *}$, Hadi Jatmiko ${ }^{2}$ \\ ${ }^{1}$ Jurusan Ilmu Pemerintahan, Universitas Muhammadiyah Jember \\ 2, Jurusan Perhotelan, Universitas Muhammadiyah Jember \\ ${ }^{1}$ putri.ra@unmuhjember.ac.id, ${ }^{2}$ hadijatmiko@unmuhjember.ac.id
}

\begin{abstract}
This PKM aims to solve the problems of Al Mumtaz problems with Disabilities Using Technology Based on Community Inclusion and Disabilities, People with Disabilities who are Blind and Mild Daksa Era of New Normal in Banyuwangi Regency. Braille Digital Marketing Umkm Al Mumtaz Disability Education Using AI Technology Based on Community Inclusion and Disabilities People with Visual and Mild Disabilities Era New Normal in Banyuwangi Regency, aims to overcome the problem of disabilities A / Blind and mild D (1) Lack of Partner knowledge related to Digital Marketing 2) Decrease in consumers using Al Mumtaz Disability Tourism Edu services and Decreased Handicraft Sales during the epidemic period (3) Unavailability of Braille Digital Marketing Module, no media aids that make it easier for A / blind and mild disabilities in marketing innovation for handicraft products (4) The lack of access to information and special AI technology media for the blind in terms of improving the quality and marketing of handicraft products. The activities carried out are by holding Braille Digital Marketing training and simulations using the Braille Digital Marketing Module, including training for Braille Digital Marketing workshops using the Braille Module, collaborating with other supporting partners who have computers and braille printers in compiling the Braille Digital Marketing Module, partner assistance (UMKM Al Mumtaz) in optimizing potential. The resulting output is the increased understanding of the training participants, the Al Mumtaz youtube account of online media publications and print media, dedication articles in the form of national journals, photos and videos of activity documentation, blogs and websites.
\end{abstract}

Keywords: Braille Digital Marketing; Education for people with disabilities

\begin{abstract}
Abstrak
PKM ini bertujuan mengatasi permasalahan UMKM Al Mumtaz Eduwisata Difabel Menggunakan Teknologi AI Berbasis Komunitas Inklusi dan Difabel Penyandang Disabilitas Tunanetra dan Daksa Ringan Era New Normal di Kabupaten Banyuwangi. Braille Digital Marketing Umkm Al Mumtaz Eduwisata Difabel Menggunakan Teknologi AI Berbasis Komunitas Inklusi dan Difabel Penyandang Disabilitas Tunanetra dan Daksa Ringan Era New Normal di Kabupaten Banyuwangi, bertujuan untuk mengatasi permasalahan disabilitas A/Tunanetra dan D ringan (1) Minimnya pengetahuan Mitra terkait Digital Marketing (2) Menurunnya Konsumen yang menggunakan jasa Edu Wisata Difabel Al Mumtaz serta Menurunnya Penjualan Handicraft di Masa Pendemi (3) Belum tersedianya Modul Braille Digital Marketing, tidak adanya media alat bantu yang memudahkan bagi disabilitas A/tunanetra dan D ringan dalam inovasi pemasaran produk handicraft (4) Minimnya akses informasi dan media teknologi AI khusus bagi tuna netra dalam hal peningkatan kualitas dan pemasaran produk handicraft. Kegiatan yang dilakukan adalah dengan mengadakan pelatihan dan simulasi Braille Digital Marketing menggunakan Modul Braille Digital Marketing, meliputi pelatihan workshop Braille Digital Marketing menggunakan Modul Braille, mengadakan
\end{abstract}


kerjasama dengan mitra pendukung lainnya yang memiliki komputer dan printer braille dalam menyusun Modul Braille Digital Marketing, Pendampingan mitra (UMKM Al Mumtaz) dalam mengoptimalkan potensi. Luaran yang dihasilkan adalah meningkatnya pemahaman peserta pelatihan, akun youtube Al Mumtaz publikasi media online dan media cetak, artikel pengabdian berupa jurnal nasional, foto dan video dokumentasi kegiatan, blog dan Website.

Kata kunci: Braille Digital Marketing; Eduwisata Difabel

*Penulis Korespondensi : Putri Robiatul Adawiyah

\section{PENDAHULUAN}

UMKM Al Mumtaz Eduwisata Difabel merupakan suatu grup usaha yang beranggotakan penyandang disabilitas di Kabupaten Banyuwangi. Awalnya usaha grup ini hanya berkecimpung mengenai jasa dan usaha kesenian musik yang disewa oleh masyarakat yang memiliki acara hajatan maupun acara resmi pemerintah. UMKM Al Mumtaz sering kali menyanyikan lagu bernuansa tradisional, daerah, religi, nasional serta menyuarakan semangat bersekolah bagi penyandang difabel sejak tahun 2011 hingga awal tahun 2020, mereka sering keliling dari panggung ke panggung baik di dalam Banyuwangi maupun ke luar kota. Manajeriali operasional dan teknis oleh Bapak Mohamad Afif Khoiri, guru Sekolah Menengah Pertama Luar Biasa (SMP-LB) Banyuwangi sekaligus pembina grup band $\mathrm{Al}$ Mumtaz.Adapun anggota UMKM Al Mumtaz saat ini yang aktif mengikuti kegiatan usaha berjumlah 15 orang penyandang difabel yang terdiri dari Komunitas Inklusi dan Difabel Penyandang Disabilitas Tunanetra, Tuna Rungu dan Daksa Ringan.

Permasalahan Mitra UMKM terjadi di awal munculnya Pendemi Covid 19 yang mengakibatkan menurunnya secara drastis jumlah pengguna jasa UMKM Al Mumtaz dikarenakan adanya larangan mengadakan keramaian saat pendemi. Hal ini berimbas pada manajemen keuangan UMKM dan anggota $\mathrm{Al}$ Mumtaz. Namun pengurus Al Mumtaz berusaha untuk bangkit dan menciptakan inovasi dengan melihat berbagai peluang dan potensi yang dimiliki oleh anggota tidak hanya kesenian musik tetapi juga potensi branding handicraft yang dihasilkan penyandang disabilitas khususnya Mitra UMKM Al Mumtaz saat pendemi kurang lebih hampir 10 bulan saat masa pembatasan sosial.
Penyandang Disabilitas merupakan masyarakat yang memiliki keterbatasan indra dalam memahami lingkungan eksternalnya. Khususnya adalah Tunanetra dimana Indra penglihatan merupakan panca indra utama dan vital bagi seseorang karena dari visi yang tampak akan langsung dan lebih mudah informasi yang dilihat dari luar dan diproses oleh system informasi. Keterbatasan yang dimiliki tersebut, tidak membuat penyandang difabel putus asa dalam menyerap informasi dari luar. Penyandang tunanetra memiliki keahlian dalam seni suara biasanya mereka menjadi vokalis dalam suatu seni musik dan seni suara.

Selain itu, tunanetra memiliki kemampuan dan keahlian memijat dan massage sesuai dengan kompetensi yang diperoleh saat pendidikan di sekolah luar biasa, serta beberapa memiliki kemampuan sebagai Qori' Profesional yang menjuarai berbagai lomba serta sering menerima order jasa sebagai qori' dalam suatu acara. Berbagai upaya dilakukan untuk memudahkan penyandang difabel A agar dapat menerima akses informasi. Sedangkan untuk tuna daksa ringan dan tuna rungu mereka masih mampu melihat, serta beberapa penyandang memiliki kemampuan untuk membuat olahan kue dan handicraft.

Terlebih saat pendemi kurang lebih hampir 10 bulan saat masa pembatasan sosial mereka manfaatkan waktu dengan membuat olahan kue kering sederhana seperti ladrang karena bagi mereka tidak ada lagi keahlian lain yang mereka mliki selain kemapuan seni musik, dan pengetahuan membuat olahan kue kering sederhana yang didapatkan saat sekolah di SMPLBN dan SMALBN Banyuwangi.

Masih minimnya pengetahuan para penyandang disabilitas A/Tunanetra dan Daksa ringan khususnya anggota UMKM Al Mumtaz terkait Informasi Digital Marketing. Meskipun seluruh anggota UMKM adalah 
penyandang tunanetra dan Daksa Ringan, tetapi manajemen pengelolaan dilakukan Bapak Mohamad Afif Khoiri. Menurut beliau, akibat pendemi menyebabkan menurunnya masyarakat dan instansi sebagai konsumen yang menggunakan jasa Edu Wisata Difabel Al Mumtaz serta menurunnya pesanan handicraft dan olahan kue kering di Masa Pendemi. Selain itu, manajemen Al Mumtaz masih minim akses informasi dan media teknologi khusus bagi tuna netra dalam hal peningkatan kualitas dan pemasaran produk.

Melalui PKM ini, peserta diberikan Pelatihan Digital Marketing yang akan memberikan pemahaman mengenai manajemen pengelolaan UMKM secara digital, pembuatan website, youtube, proses pengurusan NPWP. Bukan hanya saat new normal, atau bagaimana inovasi akan muncul dari aspirasi dan masukan dari instansi terkait akan pengembangan usaha yang dilakukan oleh penyandang disablitas khususnya UMKM Al Mumtaz. Pelatihan Digital Marketing sangat diperlukan untuk mengetahui seberapa jauh mereka memahami kualiatas layanan, pemasaran menggunakan media digital, promosi digital, publikasi website dan youtube, serta nantinya akan ada perhatian khusus dari pemerintah terkait kompetensi yang dimiliki penyandang yang berada dalam manajemen UMKM Al Mumtaz di Kabupaten Banyuwangi.

Kelompok Penyandang Difabel merupakan kelompok yang harus memperoleh perhatian lebih dari pemerintah dan masyarakat agar mereka dapat memperoleh haknya sabagaimana manusia normal yang lainnya. Era New Normal yang mulai berlaku di Kabupaten Banyuwangi, menjadi suatu peluang dan kesempatan bagi UMKM Al Mumtaz untuk bangkit dari permasalahan. Selain mulai berupaya untuk memasarkan jasa secara konvensional, para anggota mulai beralih sementara untuk mengambil peluang handicraft dan olahan kue tradisional yang dilakukan saat masa Pembatasan sosial sehingga saat ini yang dibutuhkan adalah inovasi untuk mulai memunculkan kembali produk jasa kesenian yang mereka hasilkan.

\section{METODE}

Metode pelaksanaan pengabdian ini dilakukan sesuai protocol kesehatan, melalui acara Pelatihan dan sharing diskusi. Di awal acara bapak Afif selaku pembina usaha, memberi pendahuluan mengenai sejarah dan latar belakang munculnya usaha Al Mumtaz. Materi diberikan oleh pembicara pertama Ibu Putri Robiatul Adawiyah mengenai analisis swot hambatan dan kendala yang dihadapi oleh Al Mumtaz.

Materi yang kedua diberikan oleh bapak Hadi Jatmiko menggunakan zoom, mengenai cara pengurusan NPWP, membuat akun youtube, promosi usaha melalui digital marketing serta strategi usaha yang dapat dilakukan. Di akhir acara, sharing diskusi dengan peserta, problem solving pengembangan usaha.

\section{HASIL DAN PEMBAHASAN}

Pelaksanaan pengabdian ini dilaksanakan di hari Kamis tanggal 11 Februari 2021 di Banyuwangi dengan peserta adalah anggota dan pengurus UMKM $\mathrm{Al}$ Mumtaz Kabupaten Banyuwangi, mulai pukul 08.00 sampai pukul 13.00 bertempat di Café Mak Pon Mojopanggung. Tahap Persiapan melaksanakan koordinasi dengan mitra, mengidentifikasi potensi mitra, sosialisasi kepada peserta, mengadakan koordinasi dengan pemateri. Tahap Pelaksanaan, meliputi kegiatan pelaksanaan pelatihan, sharing diskusi, pembuatan video kegiatan. Tahap Persiapan melaksanakan koordinasi dengan mitra, mengidentifikasi potensi mitra, sosialisasi kepada peserta, koordinasi dengan Bapak Afif Khoiri selaku Pembina UMKM Al Mumtaz.

Tahap Pelaksanaan, meliputi kegiatan pelaksanaan pelatihan, simulasi kegiatan, pembuatan video kegiatan, cara membuat website, cara mengurus NPWP, dan cara membuat akun youtube. Materi pertama disampaikan oleh Ibu Putri Robiatul Adawiyah, S.Sos., M.Si. mengenai sharing permasalahan secara analisis swot. Bersama bapak Afif Khoiri, memetakan permasalahan apa saja yang ada di Al Mumtaz serta apa saja alternative solusi atas kendala yang dihadapi khususnya selama masa pendemi.

Selanjutnya melakukan tanya jawab dengan peserta pelatihan. Materi selanjutnya diberikan oleh bapak Hadi 
Jatmiko, SST.Par, M.Si berkaitan dengan bagaimana membangun badan usaha mulai dari step-step apa saja yang diperlukannya serta sarat-sarat apa saja yang diperlukan dalam pembuatan badan usaha, selain itu juga terkait dengan bagaimana membuat NPWP serta dengan syarat apa saja yang diperlukan dalam membuat NPWP tersebut, serta bagaimana cara membuat akun youtube dan bagaimana menghasilkan pendapatan melalui youtube Al Mumtaz.

Anggota mahasiswa membantu menyiapkan peralatan dan membantu saat teknis di kegiatan. Melakukan dokumentasi kegiatan, membantu peserta bila ada kesulitan, serta menyiapkan bahan dan membantu menyiapkan konsumsi yang sudah dipesan. Membantu mengedarkan presensi kehadiran, serta membantu mengolah foto dan video kegiatan yang diunggah ke youtube. Tahap Evaluasi, tim melakukan koordinasi ketua dan anggota terkait penyusunan laporan kegiatan, pembuatan laporan, publikasi kegiatan, pembuatan artikel.

Rangkuman dari kegiatan sharing dan problem solving usaha UMKM Al Mumtaz yaitu diperoleh suatu informasi bahwa, Al Mumtaz mengalami hambatan promosi kegiatan karena adanya pendemi. Menurut bapak Afif, diperoleh informasi bbahwa Al Mumtaz membutuhkan suatu operator admin official yang menangani digital marketing, yang memahami bagaimana publikasi secara digital terkait usaha.

Selain itu keterbatasan anggota dalam hal mobilitas juga menjadi kendala namun bapak Afif mengatasinya dengan cara menjemput para anggota $\mathrm{Al}$ Mumtaz saat ada latihan ataupun orderan manggung/ kegiatan. Adapun secara keseluruhan, pelaksanaan kegiatan pengabdian di UMKM Al Mmtaz Banyuwangi terlaksana dengan baik, sesuai dengan target dan harapan yang direncanakan. Link video kegiatan diunggah ke youtube: berikut linknya: https://www.youtube.com/watch?v=0Ea7jKb4gRQ

Kemudian foto-foto selama kegiatan pelaksanaan pengabdian seperti yang tampak pada gambar-gambar dibawah ini :

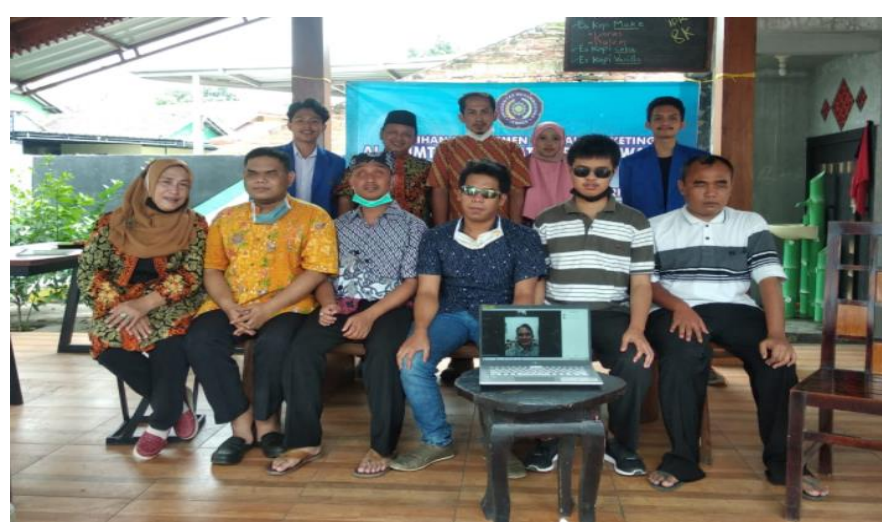

Gambar 1. Foto Bersama Peserta Pelatihan

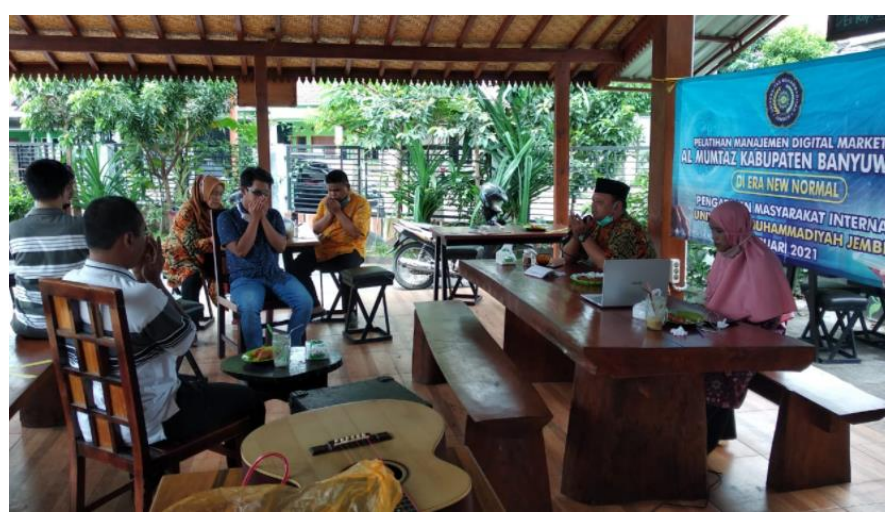

Gambar 2. Foto Saat Penyampaian Materi, Sharing Diskusi Bersama Anggota/Peserta

\section{KESIMPULAN}

Pelaksanaan kegiatan pengabdian di UMKM Al Mmtaz Banyuwangi terlaksana dengan baik, sesuai dengan target dan harapan yang direncanakan. Peserta pelatihan telah memahami dengan baik materi yang disampaikan oleh pembicara, pengurus/pembina UMKM Al Mumtaz telah memahami bagaimana cara mengembangkan usaha agar dapat meningkatkan kesejahteraan anggota dan pengurus Al Mumtaz.

Harapan kedepannya, seluruh pengurus dan anggota berkeinginan untuk diadakan pelatihan sesi kedua terkait tindak lanjut pengembangan usaha.

\section{UCAPAN TERIMA KASIH}

Terimakasih kami ucapkan kepada Bapak M. Afif Khoiri M.Pd yang membantu kami dan membarikan kesempatan untuk membimbing kelompok Usaha $\mathrm{Al}$ 
Mumtaz dalam pengembangan usaha dan pemberdayaan masyarakat disabilitas dalam usaha seni dan budaya, dan tak lupa juga kami ucapkan kepada Lembaga penelitian dan pengabdian Universitas Muhammadiyah Jember yang telah mendanai terkait dengan kegiatan ini.

\section{DAFTAR PUSTAKA}

Anon., 2020. jurnal Enterpreneur. [Online] Available at: https://www.jurnal.id/id/blog/2018-4langkah-membangun-branding-produk-agar-mudahdikenal-banyak-orang/ [Accessed 10 2020].

Anon., 2020. 2 koinworks. [Online] Available at: koinworks.com/blog/langkah-untukmembangun-brand-bisnis/

[Accessed 10 2020].

Anon., $2020 . \quad$ nasiyah. [Online] Available at: http://nasyiah.or.id/Welcome/Program_unggulan/5

[Accessed 10 2020].

Anon., 2020. publikasi IPB. [Online] Available at: $\quad$ http://publikasi.mb.ipb.ac.id/?cat $=2$ [Accessed 10 2020].

Anon., 2020. publikasiilmiah.ums. [Online] Available at: https://publikasiilmiah.ums.ac.id/handle/11617/9992 [Accessed 10 2020].

Catharine, S. . B., 2019. Creating a Brand Identity: A Guide for Designers. s.l.:Laurence King Publishing.

Johnson, M., 2019. Branding: In Five and a Half Steps. s.1.:Thomas and Hudson Publiser.

Moleong, L. J., 1992. Metode Penelitian Naturalistik Kualitatif. Bandung: Remaja Rosdakarya.

Olins, W., 2018. Brand New: The Shape of Brands to Come. s.l.:Thames and Hudson.

Rahmat, J., 2000. Metode Penelitian Komunikasi : Dilengkapi Dengan Analis Statistik. Bandung: Remaja Rosdakarya

S., 2002. Psikologi Remaja. Jakarta: Raja Grafindo Persada.

Sumarwan, U., 2018. Riset pemasaran dan konsumen. bandung: alfabeta. 